\title{
p53 - PROGNOSTIC FACTOR OF MALIGNANT TRANSFORMATION OF BARRETT'S ESOPHAGUS
}

\author{
René Aujeský R * , Marián Hajdúch ${ }^{\mathrm{b} *}$, Čestmír Neoral ${ }^{\mathrm{a}}$, Vladimír Krála ${ }^{\mathrm{a}}$, Lucie L’ubušskác, \\ Tomáš Bohanes ${ }^{\mathrm{a}}$, Jiří Klein ${ }^{\mathrm{a}}$, Radek Vrba ${ }^{\mathrm{a}}$, Petr Dráč ${ }^{\mathrm{d}}$ \\ a $I^{\text {st }}$ Clinic of Surgery, Teaching Hospital Olomouc, Czech Republic \\ ${ }^{b}$ Laboratory of Experimental Medicine, Department of Pediatrics, Faculty of Medicine, Palacky University and Teaching \\ Hospital Olomouc, Czech Republic \\ c Department of Surgical Intensive Care, Teaching Hospital Olomouc, Czech Republic \\ ${ }^{d} 2^{\text {nd }}$ Clinic of Surgery, Teaching Hospital Olomouc, Czech Republic \\ * Both authors equally contributed to the work \\ e-mail: rene.aujesky@fnol.cz
}

Received: May 16, 2005; Accepted (with revisions): June 30, 2005

Keywords: Esophagus/Esophageal cancer/p53/Barrett's esophagus

The most significant precancerosis in the esophageal cancer is Barrett's esophagus. The risk of malignant transformation is determined primarily in accordance with the degree of dysplastic alterations of the mucosa. Indication of "preventive" extirpation of the esophagus should be supported by other factors, for example by detection of p53 mutation or expression.

The study reports on the evaluation of a group of 20 patients with Barrett's esophagus treated at the $1^{\text {st }}$ Department of Surgery, the p53 level and its correlation with histological findings evaluated in these patients.

A good correlation was found between the grade of Barrett's esophagus dysplasia and high p53 positivity. This correlation was also confirmed by detection of early carcinoma in patients with "preventive" extirpation of the esophagus due to a high-grade dysplasia.

Preliminary results show that examination of $\mathrm{p} 53$ level in specimens taken from the esophageal mucosa may be helpful for the estimation of malignant potential of the dysplastic mucosa.

\section{INTRODUCTION}

Carcinoma of the esophagus is a malignant disease with one of the worst prognosis. Although $60 \%$ of patients after surgical therapy survive one year, 5-year survival ranges from 8 to $12 \% 1,11,16,18-20$. The prognosis of patients with malignant esophageal tumor is influenced not only by correct treatment but primarily by timely detection. From the long-term survival point of view, the most promising is a detection of the disease in its early stage and its treatment at the phase of precancerosis ${ }^{2,12,21}$. The most significant precancerosis in the case of esophageal carcinoma is considered Barrett's esophagus. In this case, the selection of therapy is governed by the degree of danger of its malignant transformation, which is currently determined primarily in accordance with the degree of dysplastic alterations in Barrett's mucosa ${ }^{15}$. Indication for extirpation of the esophagus carrying the serious risk of malignization of Barrett's esophagus must be supported by other factors. One of the most significant of these is determination of $\mathrm{p} 53$ mutations, which belongs among the most important oncosuppressors ${ }^{3}$.

\section{MATERIAL AND METHODS}

20 patients treated for esophageal reflux disease at the $1^{\text {st }}$ Clinic of Surgery, Teaching Hospital Olomouc, in whom the endoscopic finding was consistent with Barrett's esophagus, were selected for the study. In all patients we carried out endoscopical biopsy of the esophageal mucosa, stained with $2 \%$ Lugol's solution. The samples were collected in 2-3 levels from the border of both epithelia in aboral direction. In all cases we evaluated the correlation of the endoscopic Barrett's mucosa finding with results of the histological examination and also p53 levels in both histologically proven Barrett' mucosa and in cases, when Barrett's esophagus was not confirmed by the histological examination. The $\mathrm{p} 53$ expression was evaluated in paraffin embedded bioptic samples using indirect immunohistochemistry. Tissue samples with $>10 \%$ of positive nuclei of epithelial cells were considered as positive. In samples taken from Barrett's mucosa we focused on the comparison of $\mathrm{p} 53$ expression versus the grade of epithelial dysplastic alterations. 


\section{RESULTS}

Of the total of 20 patients, Barrett's esophagus was histologically confirmed in 14 cases. In the remaining 6 patients, necrosis, ulceration and non-specific alterations were found. Of 14 patients with histologically proven Barrett's esophagus, in 6 patients there was found highgrade dysplasia, in 4 patients low to medium grade dysplasia and in 2 patients there were found no dysplastic alterations.

In all 6 patients with the high-grade Barrett's esophagus dysplasia, p53 level was highly positive. In 5, extirpation of the esophagus was carried out and early carcinoma was detected in the resected esophagus in all of these patients. In one case, on a female patient request, we performed a laparoscopic fundoplication only and this patient is still closely checked.

In 4 patients with low to medium grade Barrett' esophagus dysplasia high $\mathrm{p} 53$ positivity was found and 2 cases were negative. 4 patients with no dysplastic changes had negative $\mathrm{p} 53$.

In a group of 6 patients where the endoscopic image of Barrett' esophagus was not histologically confirmed high p53 positivity was found in 2 patients with a histological finding of necrosis or ulceration, in 4 remaining cases where only a reflux inflammation was histologically described p53 level was negative.

\section{DISCUSSION}

Currently, in the case of Barrett's esophagus, the stage of dysplastic alterations is one of the most valid factors for predicting its malignancy ${ }^{13}$. Nevertheless, this criterion is not absolute. The lowest risk of development of adenocarcinoma is in Barrett's esophagus without dysplastic changes or perhaps at a stage of low grade dysplasia. In this case we can expect that if the causes for development of Barrett's esophagus are removed, the development of dysplastic alterations stops at the existing level. Unfortunately, no currently available therapy of esophageal reflux disease can be one hundred percent successful in complete curing of Barrett's mucosa and also local operations on the mucosa are, for the time being, very unreliable and, in addition, very risky ${ }^{22}$. Nevertheless, even at the stage of low or medium grade dysplasia, effective solution of esophageal reflux should be sufficient. If this problem is eliminated, in most cases there is no further progression of dysplastic alterations and the process is stabilized $^{6}$. The situation is totally different in patients with high grade dysplasia of Barrett's mucosa. This finding is very serious and represents a high risk of development for esophageal carcinoma ${ }^{14,17,23}$. In spite of available diagnostic methods, it has not been so far preoperatively and unequivocally possible in these cases to differentiate between dysplastic alterations and intra-epithelial carcinoma. Unfortunately, the differentiation is fundamentally significant for the patient's future. For this reason, in the case of high grade dysplasia of Barrett's mucosa, many surgical departments advocate esophagus extirpation. The most convincing argument for esophagus resection for diagnosis of high grade dysplasia is the fact, that foci of early stage carcinoma are found in the resected esophagus in $40-70 \%$ of the cases ${ }^{4,5,7-10}$. In spite of the substantial decrease in lethality and morbidity in esophagus resections in the last decade, esophagus extirpation remains a serious operation representing for the patient not only risk, but even in the case of successful operation, impact on the quality of the patient's life. Therefore, the indication for esophagus resection for unverified malignancy is considered very problematic. For this reason every piece of information, supporting actual risk of Barrett's mucosa malignant transformation and subsequently justifying resection, is very useful. One possibility is a proof of gene p53 mutation from biopsy specimen taken from a suspected area of Barrett's mucosa.

Protein / gene p53 is one of the best known and the most important oncosuppressors. Its mutation is found in more than $60 \%$ of all human tumors. In the case of esophageal carcinoma, mutation of this protein is detected in up to $80 \%$ of cases. p53 protein is an important transcription factor which is sensitive to DNA damage. In the

Table 1. Results of analysis of p53 in our group of patients.

\begin{tabular}{|c|c|c|}
\hline $\begin{array}{l}\text { Esophageal Reflux Disease patients - endoscopic image of Barrett's } \\
\text { esophagus }(\mathbf{n}=\mathbf{2 0})\end{array}$ & p53 positive & \multicolumn{2}{|c|}{ p53 negative } \\
\hline Barrett's esophagus histologically confirmed $(\mathrm{n}=14)$ & 6 & 0 \\
\hline high grade dysplasia versus ca [6] & 2 & 2 \\
\hline low and medium grade dysplasia & 0 & 4 \\
\hline no dysplasia & & \\
\hline Barrett's esophagus histologically not confirmed $(\mathrm{n}=6)$ & 2 & 0 \\
\hline necrosis and ulceration & 0 & 4 \\
\hline non-specific changes & & \\
\hline
\end{tabular}


case that such damage occurs, the cell triggers p53 gene transcription and subsequently its gene product activates a group of other genes, which participate in 1) proliferation inhibition of the damaged cell, (protein p21WAF1), 2) DNA repair (GADD45), 3) in the case of damage which is beyond repair, it triggers programmed cell death - apoptosis (protein bax). p53 protein itself is inactivated through bond with MDM2 protein after completing its biological function.

Transcription of this protein is also activated through p53. It is clear from the above, that mutation and with it p53 functional inactivation leads to the loss of control of cell proliferation, inability of the cell to restore damaged DNA, to trigger apoptosis and, not least, to inactivate p53 protein. Based on this principle a methodological procedure was created that we used for identification of the cells bearing p53 mutation gene based on p53 expression in patients with Barrett's esophagus. Instead of complicated and costly screening, p53 protein accumulation was examined in the tumor tissue by immunohistochemical techniques. We based this on the assumption, that functionally significant p53 mutation causes MDM2 protein absence and this subsequently disables p53 protein degradation.

The basic condition for success in examination of dysplastic epithelium or even epithelium with malign transformation is meticulous collection of the affected tissue. We utilized the effect of $2 \%$ Lugol's solution, which stains only normal mucosa, and for endoscopic biopsy we selected non-dyed sections of Barrett's mucosa.

Unfortunately, our patient group was too small to enable us to provide unequivocal criteria. Certain conclusions, however, can be made. In the case of high grade dysplasia, p53 protein cumulation was high in all patients. This made it easier for us to indicate esophageal extirpation in 5 patients, which was subsequently proved to be totally justified. In all cases, intra-epithelial carcinoma was found in definite histological examination of resected esophagus. In the case of low to medium grade dysplasia, p53 protein cumulation was high in half of the cases, the other half was negative. This finding justified the indication of anti-reflux operation, always in the form of laparoscopic fundoplication and also regular dispenzarization. In the case of all patients with Barrett's esophagus without proven dysplastic alterations in mucosa, p53 level was negative, which corresponds to a very low risk of malignancy, providing effective reflux elimination, in our case by laparoscopic fundoplication. Relatively surprising results were registered in patients, where the endoscopic image imitated an image of advanced Barrett's esophagus, but which was not confirmed by histological examination. Here in 2 patients with a histological finding of ulceration and necrosis, p53 level was highly positive, while in the remaining 4 patients, where only normal reflux inflammation in histological examination was described, p53 level was negative. This might mean that not only Barrett's mucosa finding with a reflux esophageal disease justifies a strict dispenzarization or effective therapy. In the same way, ulceration or necrosis finding is also necessary to consider as a potential factor for malign transformation of the esophagus mucosa and p53 accumulation may be here a marker for the degree of danger of the malignant transformation.

\section{CONCLUSION}

The preliminary results show that examination of $\mathrm{p} 53$ level in specimens taken from the esophageal mucosa may be helpful for estimation of malignant potential of the dysplastic mucosa. It is important not only in case of Barrett's esophagus but, as our data showed, also in other lesions like ulcerations etc. Only a long term follow-up of patients with higher level of p53, after antireflux procedure, may improve our knowledge about its importance in these patients. Increasing the number of patients in the study group will be very important for confirming the benefit of the method, too.

\section{ACKNOWLEDGEMENT}

This work was supported by the Czech Ministry of Education (MSM 6198959216).

\section{REFERENCES}

1. Akiyama H. (1980) Surgery for carcinoma of the esophagus. Curr Probl Surg 17, 54-120.

2. Akiyama, H. Surgery for Cancer of the Esophagus. Baltimore: Williams \& Wilkins; 1990

3. Casson AG, Manolopoulos B, Troster M, Kerkvliet N, O’Malley F, Inculet R, Finley R, Roth JA. (1994) Clinical implications of p53 gene mutation in the progression of Barrett's epithelium to invasive esophageal cancer. Am J Surg 167, 52-7.

4. Collard JM, Romagnoli R, Hermans BP, Malaise J. (1997) Radical esophageal resection for adenocarcinoma arising in Barrett's esophagus. Am J Surg 174, 307-11.

5. Csendes A, Braghetto I, Burdiles P, Diaz JC, Maluenda F, Korn O. (1997) A new physiologic approach for the surgical treatment of patients with Barrett's esophagus. Ann of Surg 226, 123-33.

6. DeMeester SR, Campos GM, DeMeester TR, Bremner CG, Hagen JA, Peters JH, Crookes PF. (1998) The impact of an antireflux procedure on intestinal metaplasia of the cardia. Ann Surg 228, 547-56.

7. Edwards MJ, Gable DR, Lentsch AB, Richardson JD. (1996) The rationale for esophagectomy as the optimal therapy for Barrett's esophagus with high-grade dysplasia. Ann of Surg 22, 585-59.

8. Ferguson MK, Naunheim KS. Resection for Barrett's mucosa with high-grade dysplasia and early adenocarcinoma. Comparison of endoscopic biopsy and surgical pathology findings. (1997) J Thorac Cardiovasc Surg 114, 824-29.

9. Heitmiller RF, Redmond M, Hamilton SR. (1996) Barrett's esophagus with high-grade dysplasia. Ann of Surg 224, 66-71.

10. Hölscher AH, Bollschweiler E, Schneider PM, Siewert JR. (1997) Early adenocarcinoma in Barrett's oesophagus. Br J Surg 84, 1470-73.

11. Huang GJ, Wang LJ, Liu JS, Cheng GY. (1985) Surgery of esophageal carcinoma. Semin Surg Oncol 1, 74-83.

12. Huang GJ. The management of early cancer of the esophagus. In: Jamieson GG, editor. Surgery of the Esophagus. Edinburgh: Churchill Livingstone; 1988, p. 629-34. 
13. Kuwano H, Baba K, Ikebe M, Adachi Y, Toh Y, Sugimachi K. (1993) Histopathology of early esophageal carcinoma and squamous epithelial dysplasia. Hepatogastroenterology 40, 222-5

14. Lagergren J, Bergstrom R, Lindgren A, Nyren O. (1999) Symptomatic gastroesophageal reflux as a risk factor for esophageal adenocarcinoma. N Engl J Med 340, 825-31.

15. Lightdale CJ. Barrett's Esophagus: Practical Guidelines for Surveillance and Management. [Annual AGA Spring Postgraduate Course, Session I: Esophagus and Stomach]. Program and Abstracts of Digestive Disease Week 2001; May 19-23, 2001; Atlanta

16. Mueller JM, Jarczyk AJ, Huber P, Pichlmayer H. (1988) Ergebnisse der Resektion der Speiseroehre wegen eines Carcinomas. Chirurg 59, 398-406.

17. Navab F, Avunduk C, Gang D, Frankel K. (1996) Bulimia nervosa complicated by Barrett's esophagus and esophageal cancer. Gastrointest Endosc 44, 492-94.

18. Orringer MB. Transhiatal esophagectomy for carcinoma . In: Siewert JR, Hoelscher AH, editors. Diseases of the Esophagus. Berlin Springer-Verlag; 1987, p. 393-396.
19. Siewert JR, Hoelscher AH, Adolf J, Bartels H. Esophageal cancer: en bloc esophagectomy with mediastinal lymphadenectomy and esophageal reconstruction with delayed urgency. In: Siewert JR, Hoelscher AH, editors. Diseases of the Esophagus. Berlin: Springer-Verlag; 1987, p. 390-393.

20. Skinner DB. Recent results of esophageal cancer surgery in North America. In: Siewert JR., Hoelscher AH, editors. Diseases of the Esophagus. Berlin: Springer-Verlag; 1987, p. 645-51.

21. Skinner DB, Ferguson MK, Soriano A, Little AG, Stazsak VM. (1986) Selection of operation for esophageal cancer based on staging. Ann Surg 204, 391-401.

22. Spechler SJ. What's new in Barrett's [Annual AGA Spring Postgraduate Course, Session I: Esophagus and Stomach]. Program and Abstracts of Digestive Disease Week; May 20-24, 2000; San Diego, California.

23. Weston AP, Badr A, Hassanein RS. (1999) Prospective multivariate analysis of clinical, endoscopic, and histologic factors predictive of development of Barrett's multifocal high-grade dysplasia or adenocarcinoma. Am J Gastroenterol 94, 3413-19. 